\title{
Temperature-controlled molecular depolarization gates in nuclear magnetic resonance ${ }^{* *}$
}

\author{
Leif Schröder*, Lana Chavez, Tyler Meldrum, Monica Smith, \\ Thomas J. Lowery, David E.Wemmer, Alexander Pines
}

\footnotetext{
* Dr. L. Schröder, Dr. L. Chavez, T. Meldrum and Prof. A. Pines:

Lawrence Berkeley National Laboratory

Materials Sciences Division

and

University of California Berkeley

Department of Chemistry

Berkeley CA 94720 (USA)

Fax: (+1) 510-486-5744

E-mail: LSchroeder@lbl.gov, Pines@berkeley.edu

M. Smith

Lawrence Berkeley National Laboratory

Physical Biosciences Division

and

University of California Berkeley

Biophysics Graduate Group

Berkeley CA 94720 (USA)

Dr. T. J. Lowery and Prof. D. E. Wemmer

Lawrence Berkeley National Laboratory

Physical Biosciences Division

and

University of California Berkeley

Department of Chemistry

Berkeley CA 94720 (USA)

Current address of Dr. T. Lowery:

T2 Biosystems

Cambridge MA 02141 (USA)
} 
**Research and experiments were supported by the Director, Office of Science, Office of Basic Energy Sciences, Materials Sciences and Engineering Division, of the US Department of Energy under Contract No. DE-AC02-05CH11231. Dr. Schroeder's position was supported by the Deutsche Forschungsgemeinschaft (SCHR 995/1-1) through an Emmy Noether Fellowship. Dr. Lowery acknowledges the Graduate Research and Education in Adaptive bio-Technology (GREAT) Training Program of the UC system wide Biotechnology Research and Education Program (\#2005-264).

\section{DISCLAIMER}

This document was prepared as an account of work sponsored by the United States Government. While this document is believed to contain correct information, neither the United States Government nor any agency thereof, nor The Regents of the University of California, nor any of their employees, makes any warranty, express or implied, or assumes any legal responsibility for the accuracy, completeness, or usefulness of any information, apparatus, product, or process disclosed, or represents that its use would not infringe privately owned rights. Reference herein to any specific commercial product, process, or service by its trade name, trademark, manufacturer, or otherwise, does not necessarily constitute or imply its endorsement, recommendation, or favoring by the United States Government or any agency thereof, or The Regents of the University of California. The views and opinions of authors expressed herein do not necessarily state or reflect those of the United States Government or any agency thereof or The Regents of the University of California.

Suggestion for table of contents (including file TOC_figure):

Down the drain: Cryptophane cages in combination with selective radiofrequency spin labeling can be used as molecular 'transpletor' units for transferring depletion of spin polarization from a hyperpolarized 'source' spin ensemble to a 'drain' ensemble. The flow of nuclei through the gate is adjustable by the ambient temperature, thereby enabling controlled consumption of hyperpolarization.

\section{$\underline{\text { Keywords: }}$}

biosensors, caged compounds, imaging agents, thermometry, xenon 
The potential of nuclear magnetic resonance (NMR) to yield spectroscopic and imaging (MRI) information based on molecule-specific signals is often impeded by its intrinsic low detection sensitivity. Amplifying the available magnetization has been the focus of many studies, leading to various hyperpolarization (hp) techniques such as hp noble gases $(1,2)$, para-hydrogen induced polarization transfer $(3,4)$, or dynamic nuclear polarization (5). Exploiting chemical exchange of nuclei of a hyperpolarized reservoir in combination with a mechanism of gated transfer onto the molecule of interest would provide optimized, controlled 'utilization' of the hyperpolarization (Fig 1a), hence avoiding polarization losses during transfer reactions. Since exchange rates depend on the ambient temperature, one can tune the amplification achieved by transferring information from a low-concentration target pool onto the high-concentration reservoir pool. Here, we demonstrate implementation of this concept using molecular cages to host hp xenon and apply this approach to non-invasive molecular temperature sensing.

Cryptophane cages temporarily encapsulate xenon (6) and facilitate functionalized molecular biosensors that combine high specificity in detecting biomolecules and high sensitivity of $1 p{ }^{129} \mathrm{Xe}$ (7). The spins of bound nuclei can be selectively depolarized with rf pulses because of the unique chemical environment offered by the cage. Subsequent release into the bulk pool changes the net magnetization in the surrounding medium. The Hyper-CEST technique allows for efficient depolarization transfer (8) by using continuous wave (cw) irradiation ("saturation" of the spin ensemble) for a few seconds.

When using temperature to control depolarization transfer, three effects should be considered: First, increasing temperature increases the exchange rate of xenon with the cage molecules $(6,9,10)$. Second, the binding constant of the cage-xenon complex tends to increase as temperature increases (11), making more xenon susceptible to selective saturation. Third, since the solubility of xenon in water decreases with increasing temperature up to ca. $310 \mathrm{~K}$, the resulting smaller reservoir pool is easier to saturate. 
However, temperature changes will only be of advantage if the significantly reduced residence time of the xenon inside the host will not cause a dramatic loss in saturation efficiency. The biosensor together with a selective rf pulse is expected to act similar to a transistor. Figure $1 \mathrm{~b}$ explains the concept of this "transpletor" that transfers magnetization depletion by adjusting the flow of saturated xenon. Initially, the pool of free atoms represents the source. Entering the host makes them sensitive to selective depolarization. The cage therefore represents the gate that must be passed to enter the pool of depolarized nuclei that corresponds to the drain. Changes of the flow into the drain contain combined information about changes in the exchange rate and the saturation efficiency. Ultimately, increasing the temperature should induce a stronger source-to-drain current.

This temperature-gated amplification was demonstrated by a set of signal depletion curves at different $T$. These curves display the decrease in bulk xenon magnetization as a function of saturation time, $t_{\text {sat }}$. Here, we used a biosensor that tracks avidin via its biotin moiety in aqueous solution (12). Figure 2a illustrates the significant acceleration in reaching the maximum Hyper-CEST effect for $T=290 \rightarrow 310 \mathrm{~K}$. Using the function $I_{\text {norm }}\left(t_{\mathrm{sat}}\right)=I_{0} \exp \left(-t_{\mathrm{sat}} / \tau\right)$ to model the data, the depolarization flow is proportional to the inverse of the time constant $\tau$. Figure $2 b$ demonstrates that $\tau^{-1}$ increases by more than tenfold upon heating the sample by $20 \mathrm{~K}$.

The above-mentioned problem of decreasing saturation efficiency is reflected by the observation that the increase of flow into the drain depends more on saturation power at higher $T$. The shorter residence time causes homogenous line broadening which makes an rf pulse amplitude of $B_{1}=29.1 \mu \mathrm{T}$ at $310 \mathrm{~K}$ almost two times more efficient than a pulse of $3.7 \mu \mathrm{T}$ (Fig. 2b). However, there is a temperature-gated amplification effect even for the low power pulse. This principle becomes relevant in two cases: First, the HyperCEST saturation power might be limited for $\mathrm{rf}$ safety reasons in biomedical imaging. 
Second, the use of low-bandwidth pulses is an important step for reading out different sensor signals in the same system (multiplexing, $(7,10)$ ).

The transpletor concept was implemented with a biosensor imaging setup that uses a pulse sequence with a saturation bandwidth of only $\Omega \approx 30 \mathrm{~Hz}$ (i.e., $B_{1}=1.6 \mu \mathrm{T}$ ). This should yield ineffective saturation at $T \approx 300 \mathrm{~K}$ but effective depletion transfer at slightly increased temperatures. ${ }^{129}$ Xe MRI datasets were collected using a setup described below. Figure 3a shows a coronal ${ }^{1} \mathrm{H}$ MR image of the system with two samples of agarose beads, one sample labeled with the biosensor. The signal of solution-xenon at $193.6 \mathrm{ppm}$ (aqueous solution with agarose) can be detected in a single shot slice-selective spectrum (Fig. 3b) and allows to selectively display the spatial distribution of the microscopic beads (Fig. 3c). In contrast, substantial line broadening (Fig. 3d) and low concentration make the biosensor signal at $\sim 65 \mathrm{ppm}$ undetectable without substantial signal averaging (Fig. 3e).

Figure 4 illustrates the expected temperature-gated amplification for sensor detection. At room temperature (299 K), the Hyper-CEST depletion is ineffective, as demonstrated by the signal-to-noise ratio $(\mathrm{S} / \mathrm{N})$ in a spectrum from the sensor-labeled compartment: when comparing on-resonant with off-resonant saturation, the $\mathrm{S} / \mathrm{N}$ changes only by $8 \%$ (within the noise level). Increasing $T$ by $3 \mathrm{~K}$ yields a change in $\mathrm{S} / \mathrm{N}$ of $-28 \%$. Further heating to $305 \mathrm{~K}$ results in a significant rise in flow through the gate and consequently a $46 \%$ signal depletion, clearly highlighing the sensor-free compartment.

These data illustrate that despite the reduced exposure time of nuclei to the cage environment there is a significant increase in signal contrast for higher temperatures. Substantial line broadening of bead-associated sensor (the resonance is over $200 \mathrm{~Hz}$ wide (8)) is not an issue in this case since inhomogeneous broadening, caused by immobilization, does not impede efficient saturation. Detecting structures of micrometer 
size becomes feasible with this technique, whereas conventional NMR readout fails to acquire even sufficient proton signal for localization of macromolecules.

In summary, we demonstrated temperature-controlled molecular gates for optimized use of hp nuclei in liquid state NMR. Biosensor detection now includes features of MRI thermometry (13)—which could be used to monitor hyperthermia in oncologic therapy (14)—but the concept of a transpletor also illustrates increased sensitivity at body temperature. Moreover, this concept can be applied to other problems that rely on exchangeable NMR-detected guests to reveal properties of the host structure or indirect detection of competing guests $(6,10,15,16)$. Such experiments would facilitate studies of the exchange dynamics of other nanostructure hosts (alternative cages, carbon nanotubes, zeolites (17)). In addition, both competing molecules (e.g. methanol or chloroform in solution) with comparable or higher binding constants and parameters that change the host accessibility of the hyperpolarized guest (e.g. solvation of xenon) will influence the flow of hyperpolarized nuclei through the gate and could be detected with the transpletor. In this way, depolarization transfer enables sensitivity-enhanced detection of molecules even if they usually cannot directly benefit from hp techniques. 


\section{Experimental Section}

Datasets were recorded on a 7.05 T NMR spectrometer (Varian, Palo Alto, CA) with a $10 \mathrm{~mm}$ probe. Hyperpolarized xenon $(P \approx 4.6 \%)$ was generated with a XenoSpin $^{\mathrm{TM}}$ polarizer (Amersham Health, Durham, NC) using a mixture of $89 \% \mathrm{He}$, $10 \% \mathrm{~N}_{2}$ and $1 \%$ non-enriched xenon (Isotec, Sigma Aldrich). For evaluating the signal depletion upon increasing saturation time at different temperatures, this mixture was bubbled for $25 \mathrm{~s}$ at $0.45 \mathrm{SLM}$ into an NMR tube containing ca. $2.5 \mathrm{ml}$ of $20 \mu \mathrm{M}$ biosensor solution. Gas flow was then interrupted using a stopped-flow system (18), followed by a $5 \mathrm{~s}$ delay to wait for disappearance of any bubbles. Next, the Hyper-CEST experiment started with a variable cw-saturation delay and subsequent readout of a single $300 \mathrm{~ms}$ free induction decay. The temperature of the system was controlled with the variable temperature unit of the spectrometer. After Fourier transformation and application of an apodization filter, the xenon solution peak at $192.5 \mathrm{ppm}$ was integrated to determine signal depletion.

Imaging experiments were conducted with a gradient coil assembly (Resonance Research Inc., Billerica, MA) for spatial encoding. A two-compartment phantom described previously (8) contained avidin-labeled agarose beads (Immobilized Avidin, Pierce Biotechnology, Rockford, IL) and was perfused with water $(6 \mathrm{ml} / \mathrm{min})$ that was heated before entering the magnet with a $2 \mathrm{ft}$ heating cable $(5 \mathrm{~W} / \mathrm{ft}$ power output; $\mathrm{BH}$ Thermal $^{\circledR}$ Corporation, Columbus, $\left.\mathrm{OH}\right)$ and saturated with the polarizer gas mixture $(0.65$ SLM gas flow) immediately before entering the phantom (19). One compartment contained the biosensor at $50 \mu \mathrm{M}$ concentration. A thermocouple attached to the outlet channel of the phantom was used to read the temperature of the water directly after leaving the bead volume. The maximum achievable temperature of the water was $305 \mathrm{~K}$ due to the need to keep the heating cable outside of the magnet and because of poor thermal conductivity of the tubing guiding the water.

${ }^{129}$ Xe Hyper-CEST images were acquired using a $1.5 \mathrm{~s}$ cw-pulse of $1.6 \mu \mathrm{T}$ amplitude and a slice-selective $90^{\circ}$ pulse along the $z$-dimension $(2 \mathrm{~ms}$, sinc shape, $10 \mathrm{~mm}$ slice-thickness) with subsequent 2-dimensional phase encoding $\left(12 \times 12 \mathrm{~mm}^{2}\right.$ field-ofview, matrix size $8 \times 8,10.8 \mathrm{~min}$ acquisition time). Each point in $k$-space was read out once for $64 \mathrm{~ms}$ with $100 \mathrm{kHz}$ spectral width. Post-processing using MATLAB ${ }^{\circledR}$ (MathWorks, Inc., Natick, MA) included 2-dimensional FT for spatial reconstruction after zero-filling to a $16 \times 16$ dataset and 1-D FT for spectral reconstruction. Images showing the spatial distribution of the bead signal at $193.6 \mathrm{ppm}$ were generated by 
summation of the signal intensity over 5 data points $(\approx 0.74 \mathrm{ppm})$ in the absolute spectrum and subsequent color-encoding of these values. 
a)

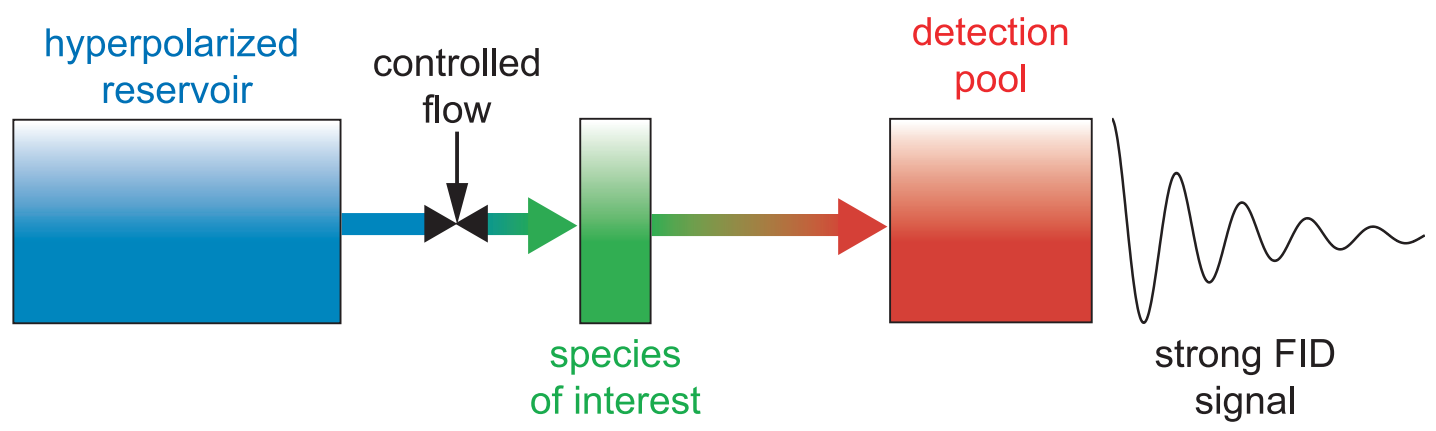

b)

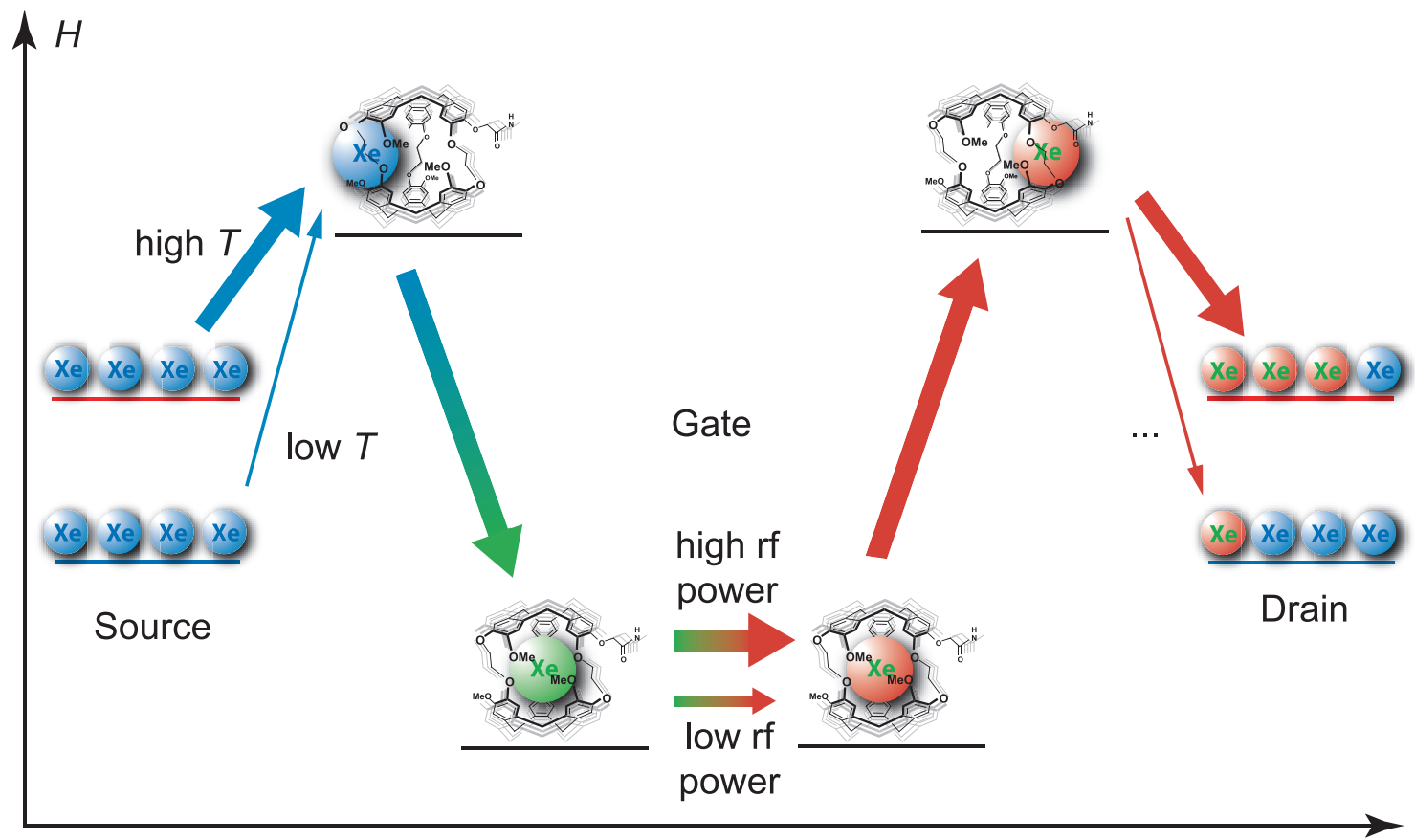

Reaction Coordinate

Figure 1:

NMR signal enhancement through transfer of magnetization and its implementation for hp xenon atoms (transpletor concept). a) Magnetization transfer using a hp reservoir picks up information from a molecule of interest at low concentration. Controlling the flow from the reservoir allows gated transfer of the information into the detection pool. b) Flow schematics of hyperpolarized magnetization using a molecular host for controlled depolarization of ${ }^{129}$ Xe guest atoms. Free hyperpolarized atoms (blue) represent the source of magnetization and can flow into the gate where they resonate at a different frequency (green) and can be saturated by a selective rf pulse. The depolarized nuclei (red) leave the cage and accumulate in the drain. Accessibility to the gate is determined by the activation barrier to enter the cage and can thus be controlled by temperature. 

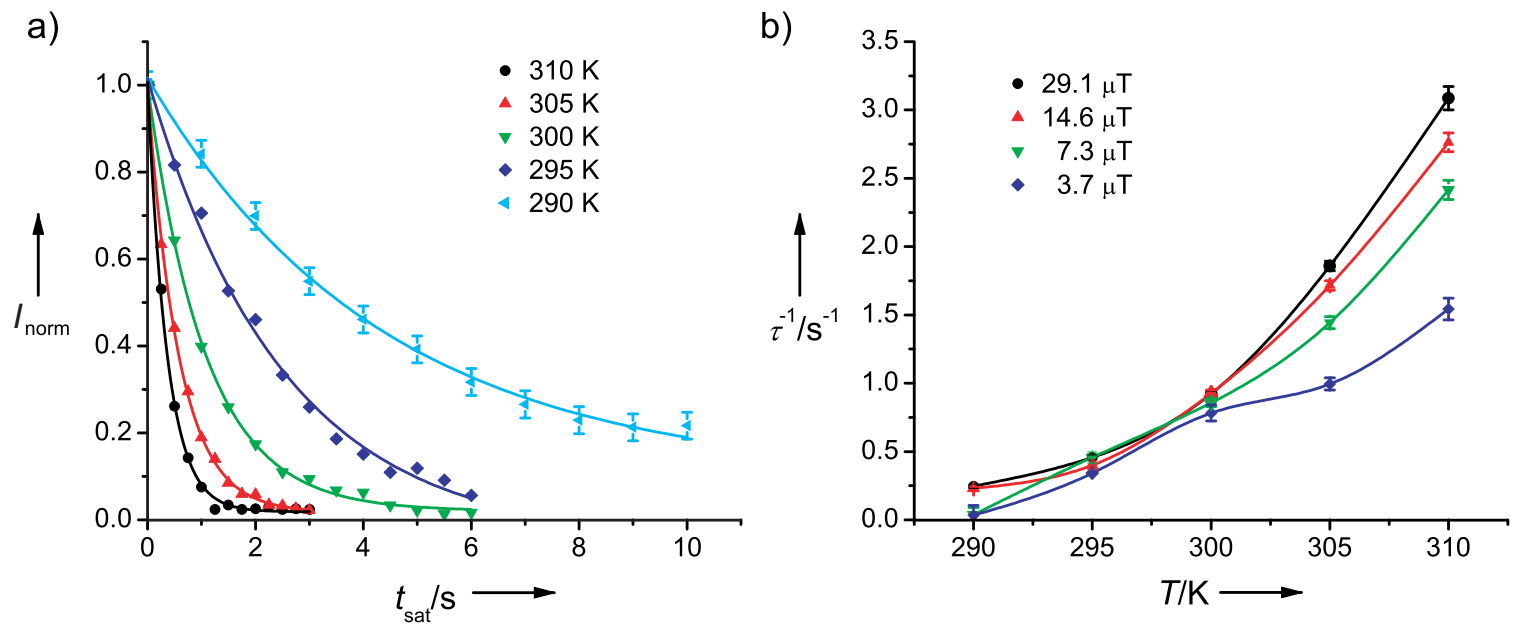

\section{Figure 2:}

\section{Source-to-drain depolarization flow control using Hyper-CEST with a cryptophane-}

A cage at different temperatures. a) Saturation curves for the normalized solution peak intensity, $I_{\text {norm }}$, in the presence of $20 \mu \mathrm{M}$ sensor concentration and $B_{1}=14.6 \mu \mathrm{T}$ saturation power at different temperatures. The time constant $\tau$ varies between $4.34 \mathrm{~s}$ for $290 \mathrm{~K}$ and $0.36 \mathrm{~s}$ for $310 \mathrm{~K}$. b) Plot of $\tau^{-1}$ from saturation curves like in a) as a function of temperature. Insufficient saturation occurs at high temperatures, as seen from the differences in $\tau^{-1}$ for different saturation powers. The pulse with $B_{1}=3.7 \mu \mathrm{T}$ has a bandwidth of $\Omega \approx 72 \mathrm{~Hz}$ and is therefore only marginally wider than the resonance to be saturated at $310 \mathrm{~K}$. Using the high power pulse $\left(B_{1}=29.1 \mu \mathrm{T}\right)$ with $\Omega \approx 614 \mathrm{~Hz}$ ensures complete saturation even at high temperatures and reflects highly efficient transfer of depleted magnetization due to increased xenon flow. 

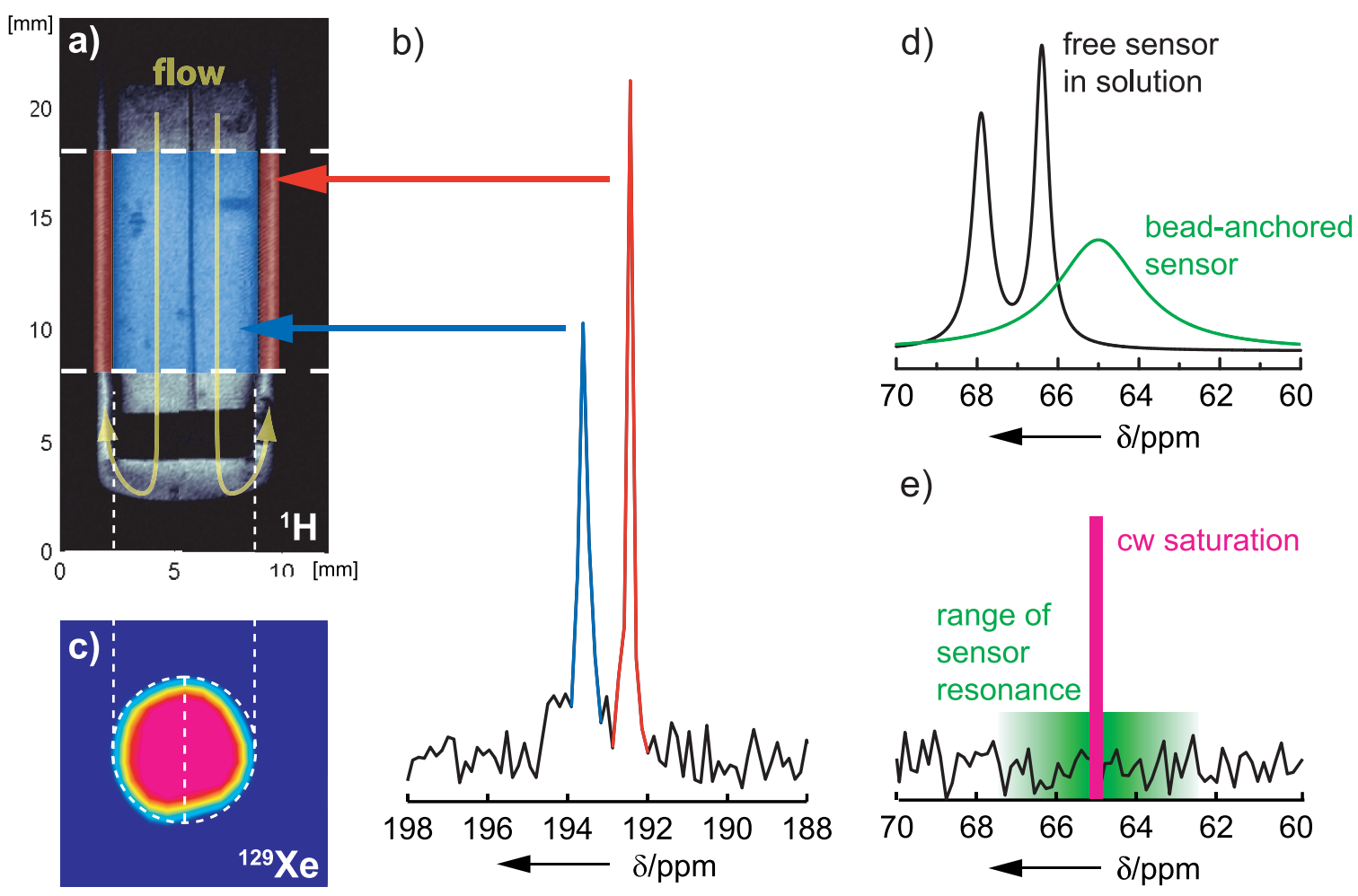

e)

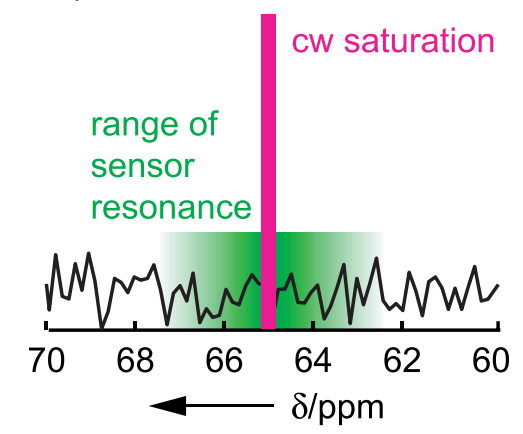

Figure 3:

Conditions for ${ }^{129} \mathrm{Xe}$ MR imaging of functionalized cryptophane cages targeting microscopic beads. a) ${ }^{1} \mathrm{H}$ coronal image $\left(12 \times 24 \mathrm{~mm}^{2}\right.$ field of view) of the perfusion phantom showing the $10 \mathrm{~mm}$ transverse slice for xenon imaging (colored overlays). The center volume with the agarose beads is split in two compartments, only one of which contains the functionalized cryptophane-A cage. The agarose-filled part of the slice (blue) is the source of a resonance at $193.6 \mathrm{ppm}$, the surrounding part of the outlet gap (red) is the source of a peak at $192.5 \mathrm{ppm}$ (see b). b) Single-shot slice-selective ${ }^{129} \mathrm{Xe}$ NMR spectrum showing the signals from the two colored regions in a). c) Transverse ${ }^{129} \mathrm{Xe}$ image $\left(12 \times 12 \mathrm{~mm}^{2}\right.$ field of view) generated from the peak at $193.6 \mathrm{ppm}$ showing distribution of the agarose beads. d) Line form changes of the biosensor signal upon immobilization to microscopic structures like agarose beads (schematic spectra with representative line widths reported in (9) and (8)) e) The biosensor resonance of $\sim 210 \mathrm{~Hz}$ line width at $65 \mathrm{ppm}$ (green box) is below the noise threshold (high-field part of the spectrum in b)). However, low-power saturation with $B_{1}=1.6 \mu \mathrm{T}$ (corresponding to a saturation bandwidth of $\sim 30 \mathrm{~Hz}$; pink bar) will yield efficient saturation transfer at high temperature (see Fig. 4). 
a)

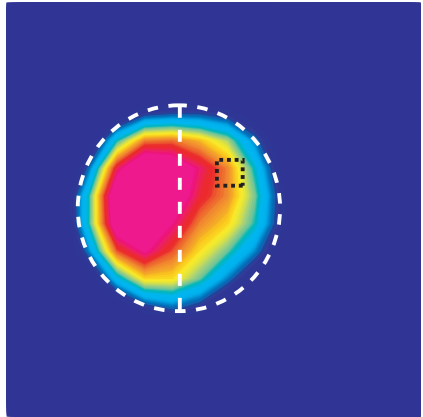

$299 \mathrm{~K}$

b)

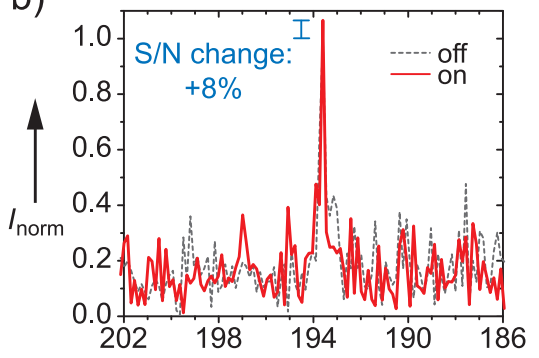

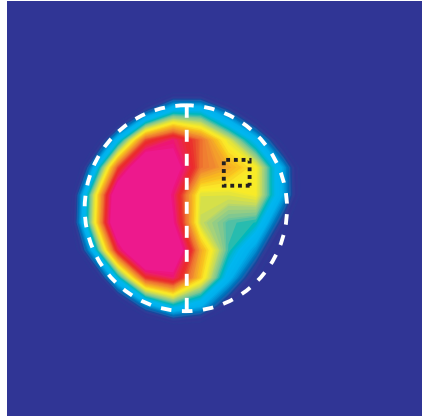

$302 \mathrm{~K}$

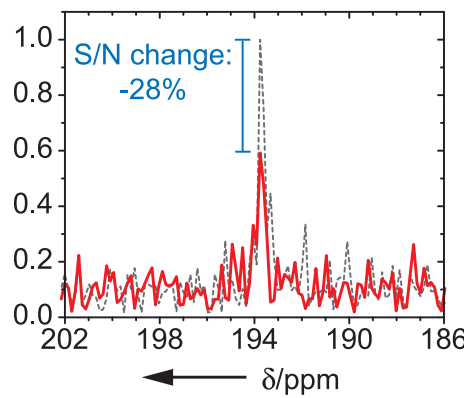

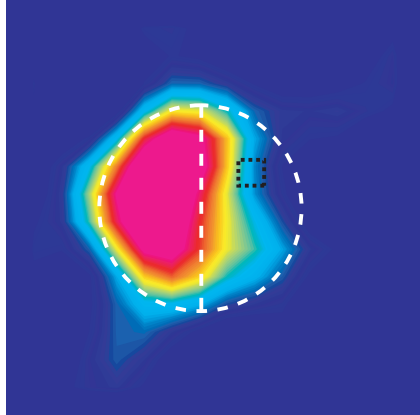

$305 \mathrm{~K}$

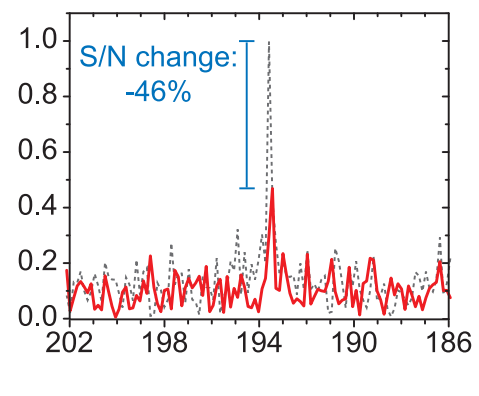

Figure 4:

Application of the transpletor concept for temperature sensitive molecular imaging.

a) Transverse ${ }^{129} \mathrm{Xe}$ images show increasing contrast when the temperature is raised from $299 \mathrm{~K}$ to $305 \mathrm{~K}$. The right compartment outlined by the contour contains the biosensor with the functionalized cryptophane-A cage that responds only weakly to on-resonant saturation with $B_{1}=1.6 \mu \mathrm{T}$ for $1.5 \mathrm{~s}$ at $299 \mathrm{~K}$. Higher temperature enhances the HyperCEST contrast and yields significantly more efficient saturation. b) Corresponding spectra from the center of the right compartment show the signal change for on-resonant saturation at different temperatures. Whereas the $\mathrm{S} / \mathrm{N}$ is almost unchanged at $299 \mathrm{~K}$, a signal decrease of $46 \%$ can be achieved after increasing the sample temperature by $6 \mathrm{~K}$. 


\section{REFERENCES}

[1] M. R. Bouchiat, T. R. Carver, C. M. Varnum, Phys. Rev. Lett. 1960, 5, 373-375.

2. B. M. Goodson, Concepts Magn. Res. 1999, 11(4), 203-223.

3. C. R. Bowers, D. P. Weitekamp, Phys. Rev. Lett. 1986, 57, 2645-2648.

4. D. Canet, C. Aroulanda, P. Mutzenhardt, S. Aime, R. Gobetto, F. Reineri, Concepts Magn. Res. Part A 2006, 28(5), 321-330.

5. D. A. Hall, D. C. Maus, G. J. Gerfen, S. J. Inati, L. R. Becerra, F. W. Dahlquist, R. G. Griffin, Science 1997, 276, 930-932.

6. K. Bartik, M. Luhmer, J.-P. Dutasta, A. Collet, J. Reisse, J. Am. Chem. Soc. 1998, $120,784-791$.

7. M. M. Spence, S. M. Rubin, I. E. Dimitrov, E. J. Ruiz, D. E. Wemmer, A. Pines, Proc. Natl. Acad. Sci. USA 2001, 98(19), 10654-10657.

8. L. Schröder, T. J. Lowery, C. Hilty, D. E. Wemmer, A. Pines, Science 2006, 314, 446-449.

9. T. J. Lowery, S. Garcia, L. Chavez, E. J. Ruiz, T. Wu, T. Brotin, J.-P. Dutasta, D. S. King, P. G. Schultz, A. Pines, D. E. Wemmer, ChemBioChem 2006, 7, 65-73.

10. G. Huber, T. Brotin, L. Dubois, H. Desvaux, J.-P. Dutasta, P. Berthault, J. Am. Chem. Soc. 2006, 128, 6239-6246.

11. P. A. Hill, Q. Wei, R. G. Eckenhoff, I. J. Dmochowski, J. Am. Chem. Soc. 2007, $129,9262-9263$.

12. T. J. Lowery, S. M. Rubin, E. J. Ruiz, M. M. Spence, N. Winssinger, P. G. Schultz, A. Pines, D. E. Wemmer, Magn. Reson. Imaging. 2003, 21, 1235-1239.

13. S. Zhang, C. R. Malloy, D. A. Sherry, J. Am. Chem. Soc. 2005, 127, 17572-17573.

14. C. Weidensteiner, B. Quesson, B. Caire-Gana, N. Kerioui, A. Rullier, H. Trillaud, C. T. Moonen, Magn. Reson. Med. 2003, 50, 322-330.

15. L. Garel, B. Lozach, J.-P. Dutasta, A. Collet, J. Am. Chem. Soc. 1993, 115, 1165211653.

16. C. Garcia, D. Humilière, N. Riva, A. Collet, J.-P. Dutasta, Org. Biomol. Chem. 2003, 1(12), 2207-2216.

17. C. J. Jameson, A. K. Jameson, R. Gerald II, A. de Dios, J. Chem. Phys. 1992, 96(3), 1676-1689.

18. S.-I. Han, S. Garcia, T. J. Lowery, E. J. Ruiz, J. A. Seeley, L. Chavez, D. S. King, D. E. Wemmer, A. Pines, Anal. Chem. 2005, 77(13), 4008-4012. 
19. C. Hilty, T. J. Lowery, D.E. Wemmer, A. Pines, Angew. Chem. Int. Ed. 2006, 45, 70-73. 
Suggestion for cover illustration:

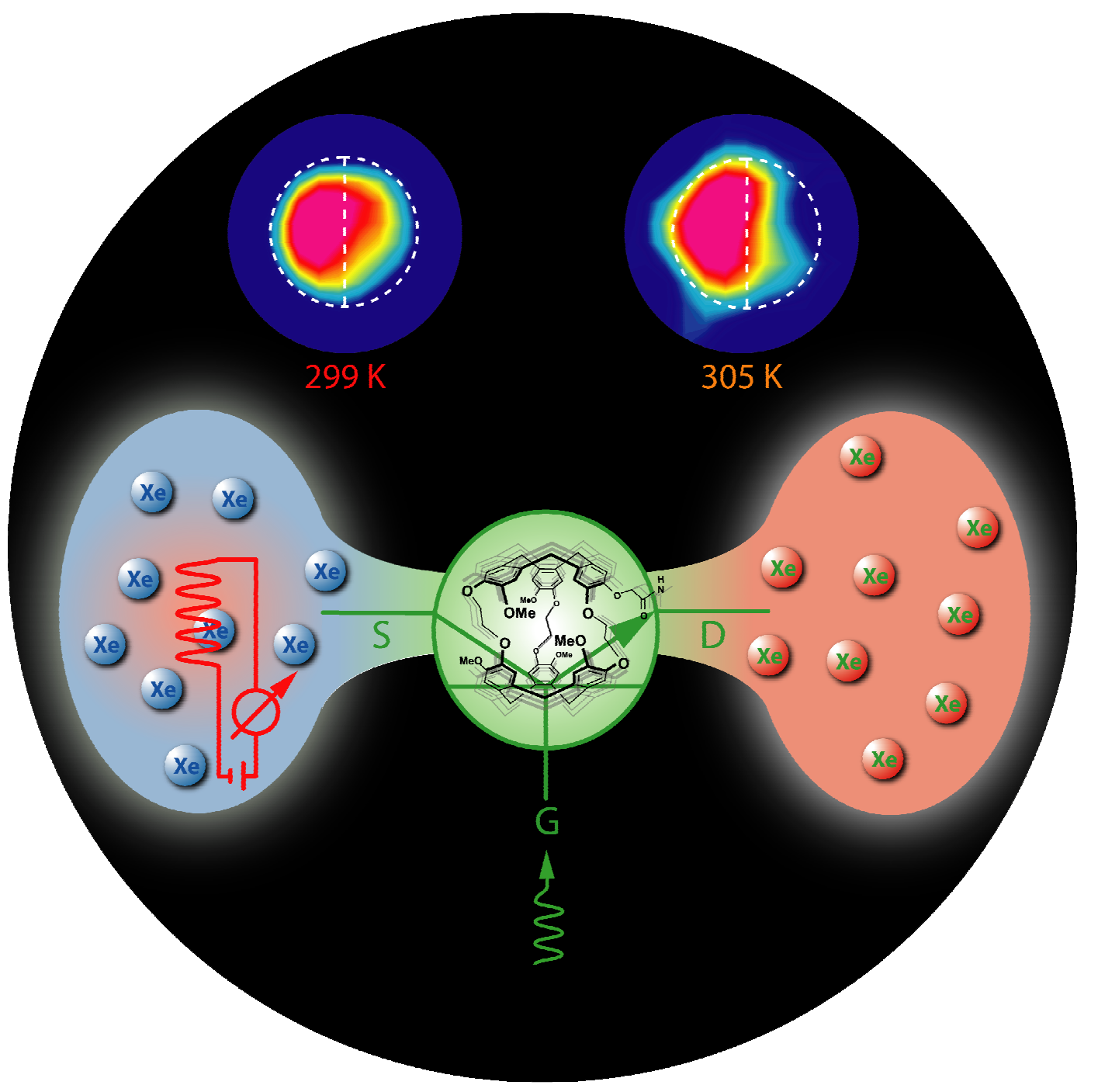

Cryptophane cages in combination with selective radiofrequency spin labeling can be used as molecular 'transpletor' units for transferring depletion of spin polarization from a hyperpolarized 'source' spin ensemble to a 'drain' ensemble. The flow of nuclei through the gate is adjustable by the ambient temperature, thereby enabling controlled consumption of hyperpolarization and temperature sensitive magnetic resonance imaging.. 